\title{
A Study of Chinese Urban History from the Perspective of Global History
}

\author{
Haochun Guan \\ Institute of History and Culture, Sichuan University, Chengdu, Sichuan Province, China
}

Keywords: Global History; A Study of Chinese Urban History; Perspective;Research areas.

\begin{abstract}
In recent years, great progress has been made in the study of Chinese urban history, and the research has gradually achieved a series of leaps from the case to the whole, from the longitudinal combing to the overall comparison and other series across. However, Chinese urban history research also faces many problems in the content, perspective and methods. Nowadays, the theory and method of research around the global history of vigorous development in the world not only contribute to propose the solution of some problems in the study of Chinese urban history, but also have a constructive role for researchers to get rid of the regional history research, to break through the study of global history under the shadow of the Western position and perspective, and establish the multi-angle, multi-vision urban history research.
\end{abstract}

\section{Introduction}

With the development of historical research, the research achievements of urban history in China have been increasing in recent years, showing great research potential and broad prospects for development. At the same time, the study of urban history in the theory, methods, ideas and other aspects are also facing a series of problems, such as the construction of its own theory, the majority of small cities and small towns and other research is not enough. In these problems, how to improve the comprehensive study on the basis of a single city, in order to fully reflect the overall and comprehensive city, to avoid the study of regional urban history in a single urban research results simple patchwork and other issues is particularly important.[1] Faced with this situation, the research methods and vision of global history recently in the academic circles of domestic and foreign has a certain effect on resolving this problem and reversing the "fragmented" trend in recent years' historical research effect. In the following, the author elaborates the significance of the theory to the study of urban history in China from the aspects of research contents, research ideas and methods.

\section{Widen the field of Chinese urban history research}

Global history attaches great importance to intercultural interaction and its role in shaping the common history of the world, so it focus more on the material aspects, including the integration of different civilizations, different ideological cultures and institutions. So Bentley in his 2002 article The New World History, noted that global history research topics mainly include "cross-cultural trade", "species spread and exchange", "cultural collision and exchange", "imperialism and colonialism", "immigration and discrete community", etc., through the study of the above objects establish The relationship between regions.[2] The view of the overall view, global perspective, interactive concept of the global history request researchers out of the limitations of the traditional national, regional, but focus on the research of the world influence imperial city in ancient China, so as to observe the uniqueness and differences between various regions, Attaches great importance to those geographical units who have high degree of internationalization, globalization and worldwide , and pay attention to the traffic cities who have global hub status, have forefront statues in exchanges ,put those cities in the center status and Sino-foreign joint transportation of the region political, economic and cultural aspects such as Beijing, Shanghai, Guangzhou, etc., into the global 
trade and cultural exchanges network, world politics to discuss. Take Shanghai as an example. The reason of the city could become an international city in modern times, not only relations with its special geographical location, but also closely related with its bring into the global geographic location center. Because of this reason, Shanghai could establish relations with Japan, east Asia, Europe and the America and other parts of the world. In this regard, the research of Shanghai urban development history, global trade, the international politics, and its geography location in the world are need to research. Traditional cities have experienced dramatic changes in modern times, and are different from the past cities in terms of size, rank, function, and so on. Therefore, in the study of Chinese modern cities, especially in the modern trading ports and coastal open cities, in Chinese and western traffic hub port cities and islands, attention should be paid to the transformation of its function and status of the shift. Many cities in the world today face a series of problems such as environment, ecology and excess capacity. This situation is especially prominent in traditional resource-oriented cities such as Daqing and Jixi. These factors led to the shortage of the power of the urban development and decline of the city. In the face of the global industrial economy the trend of adjustment, how to solve the urban function transformation become the key to reverse the decline, of course, this should also be attention needed by the urban history researchers.

In addition, under the perspective of global history to study Chinese urban history , also need to strengthen the communication between different directions of historiography to broaden the research field. In particular, China's urban history research should strengthen the cooperation between urban history and social history, political history, economic history and the other areas, the combination between urban history and ecological history, medical history, and the other special history, to inspect the relationship between global cities, research the urban social life, the change of social environment. At the same time focused on the origin, development of cities and its history and culture, also should pay attention to the relationship between city with man and nature, in-depth analysis the change between city people live and urban social customs, to deepen the study of Chinese urban history. At the same time, researchers need to constantly learn from and absorb the research results of other fields, and use multidisciplinary perspectives to broaden the field of urban history research. For example, by combining with geography to study the changes of urban geographical space and layout; Through the combination of economics to explore the urban economic development, trade relations, urban industrialization and so on. In general, the research of urban history should deep into the interior of the city to explore the relationship between the elements of the city, such as organization, personnel, commodities and trade. Look down, paying attention to medical treatment, health, charity and other undertakings in the city, the chamber of commerce, exhibition, trade associations and other organizations, schools, museums, parks and other public places, students, businessmen, intellectuals and other groups, in order to deepen the understanding of the connotation of the city, to make urban history research more stereo, fullness.

\section{Expand the scope of Chinese urban history research}

The city is the carrier of civilization. Its development has always been with the rise and fall of civilization. The global history advocates out of the limitation of region, nation and country, and takes the rise, decline and evolution of civilization as the main line, and studies from material, institutional, spiritual and cultural aspects. For that matter, in the perspective of global history to study Chinese urban, on the perspective should break through China oneself to study internal orientation and path dependence, bring urban into world history, transnational history perspective, on the background of the interaction. Therefore, in the observation space geographical point of view, people should change the previous tendency of seeing city in the central plains and the mainland, select the point of view based on the frontier, ocean and world to research city. For example, in the research of the coastal port cities,should not only change the inland limitations of previous studies that concentrate on the port city of natural geography, economic hinterland and even regional economy and domestic trade, etc., but also expand horizons, put it into the ocean history and global history, pay attention to its status and role in the area, ocean, the world trade, culture and political system, attaches great importance to the link of domestic port city and the rest of the external world port city as well as the role in the 
Marine network and even the world the network. On the view of observation, should change the vision of ever from the center to the edge, from the ethnic han to Ethnic minorities, makes urban history research become a visual angle, domain and direction of communication inland and frontier, continental and Marine, China and the world, in the change of the so-called civilization conflict model, promote their own han and other ethnic minorities, the Confucian culture and Christianity, Islam, and other religious culture exchange and interaction make a certain contribution. In addition, the researchers should also see, from traditional China to today's modern China is a huge change, and the countryside plays an important role in this process, made great sacrifices for China's industrialization and urbanization, the communication and complementary between urban and rural is the fact that the present China's urban and rural binary relation is not a sense of opposition. Therefore, Chinese urban history researchers in the study of city should not be isolated cities research, but on the point should jump out of a simple internal orientation of urban history research, standing in the perspective of the interaction between urban and rural areas to observe the development of the city and evolution, the relationship between urban and rural areas, small towns and the urban space, through the relationship between urban and rural areas in the ancient and modern, Chinese and foreign urban and rural relationship and social change, by comparison with urban and rural spatial location, history, Chinese and western urban and rural development, to explore the change and difference of urban and rural space, the characteristics and function of city, etc.

At the same time, in the research path and method, Chinese urban history researchers should also attach importance to the research idea of comparative historiography, aggressively "across the country or region's macro comparative study", with "global view", should have notice from the angle of view of interact and connect to observe the city.[4] So it is necessary to reveal the "history of interconnection" between different regions, countries and groups under certain conditions through the study of cities in one region and one network. [5]In this regard, the comparative study of Hong Kong and Shanghai by domestic scholars and the comparative study of Shanghai and Yokohama with Japanese scholars is a good example. Shanghai and Yokohama not only have a comparative in the formation of the two cities, local autonomy, business and import and export trade and so on, but also make a comparative analysis in many aspects in the spread western learning between the two cities.[6] Not only that, there are also have a comparative study of domestic cities, such as social and cultural comparison between Nanjing and Shanghai, economic comparison between Shanghai and Dalian ,the structure of city and function comparison between Wuhu and Nantong. However, this comparative study, is only the starting point, the future study of city history still need to continue to move forward, and a wide range of comparison research, in this regard, Joel Kotkin book The City: A Global History is a representative. The book with wider perspective on the history of the world cities "panoramic "scanning, in a wide range of comparison and analysis of the global city, on the basis of urban development characteristics of different historical period, put forward their views of the formation and development nature, it is instructive. Apart from this large-scale comparative study also need break through the comparison between individual countries and cities and carries out the overall comparison between different countries in the world. Break through the limitations of individuals and disciplines and conduct interdisciplinary collaborative research across the globe.

\section{Conclusion}

Of course, the mainland researchers in using and introducing the theory of global history, should have a prudent attitude towards the problems arising from the study of the history of foreign city, when communicate and exchange, translation foreign achievements with foreign country in discipline construction, cannot ignore its knowledge system, the background of social theories and its limitations. After all, the application of theory will "inevitably accompany ideology".[7] As a branch, which close links to the social science of historiography, Chinese urban history researchers in the use of global history, must base on the basis of "diversity" to the world, focusing on the "special" of the area, the national at the same time, the concept of presupposition, problem consciousness, etc should start from their own history and reality, establish a set of native characteristic urban history theory and interpretation system. On one hand, Chinese urban history researchers should communicate with 
other countries' urban history in the world. In the global history, the model of international interaction is used to break through the influence of narrow national and regional concepts and prevent the bias of value judgment. Through the establishment of the links between regional cities in the world, to get rid of the existing patterns constraint of the existing urban history study on the of individual cities. On the other hand, the researchers should also pay attention to from the most basic facts, looking for a strong concept of analysis, through research and investigation to understand the generation and development of inner logic and change, constantly communicate study practice and the existing theory, to correct and improve the existing default theory and concepts, and gradually establish a theoretical system that accord with Chinese native actual urban history research.

\section{References}

[1]He Yimin .Urban history[A]. Study on modern Chinese contemporary history [C]. Beijing, China social sciences press, 2014:395-396.

[2] Xia Jiguo, Jerry H. Bentley, The New World History [M]. Beijing,Peking University press, 2010, 44-65

[3] Mao Xi. The study of Chinese urban history in the global urban history - reading Joel kotkin: the thought of The City: A Global History [J]. Study of historiography, 2007 (4) : 147.

[4] Lee yu. Global history research: finding the way of global communication -- visiting French historian Maurice Aymard [J], China social science news, 2014-2-26.

[5] Shanghai and Yokohama joint editorial board, Shanghai archives .Shanghai and Yokohama -- two open cities in modern Asia [Z], Shanghai, East China normal university press, 1997.

[6] Joel Kotkin. Global urban history [M]. wang xu etc translate. Beijing, social sciences academic press, 2006.

[7] Philip C. C. Huang. Academic Theory and the Research on Chinese Modern History [J]. Academics, 2010.3:9 